\title{
TEACHING CHILDREN WITH NIEMANN-PICK DISEASE
}

\author{
BARBARA. C. GARTIN \\ University of Arkansas, Fayetteville \\ NIKKI L. MURDICK, JENNIFER COOLEY, \\ AND SARA BARNETT \\ Saint Louis University
}

\begin{abstract}
Author Note
Barbara C. Gartin, Curriculum and Instruction, University of Arkansas; Nikki L. Murdick, Department of Education, Saint Louis University; Jennifer Cooley, Department of Education, Saint Louis University; Sara Barnett, Department of Education, Saint Louis University.

Correspondence should be addressed to Barbara C. Gartin, Department of Curriculum and Instruction, University of Arkansas, Fayetteville, Arkansas 72701. E-mail: bgartin@uark.edu
\end{abstract}

\section{ABSTRACT}

Niemann-Pick Disease (NPD) is a group of rare inherited disorders that are both systemic and degenerative. Knowledge of the disease, its characteristics, and its progression are essential for the teacher and related service personnel to provide an appropriate educational experience for the student. For the teacher who has a student with $\mathrm{NPC}_{1}$ in his/her classroom, the focus is two-fold: first to provide a supportive academic environment for the student with $\mathrm{NPC}_{1}$ and her/his classroom peers; and, second, to provide emotional support for the student and the family. Included in this manuscript are suggested accommodations for the teacher and other therapists and related service personnel to use in providing an appropriate education for a student with $\mathrm{NPC}_{1}$. 
Niemann-Pick Disease (NPD) is a group of rare autosomal, recessive disorders that is fatal (Knox \& Ramsey, 1932). Recent research (Bergamin et al., 2013; Heath, 2008; Rodriguez-Pascau et al., 2012; Tagermo et al., 2011; Wraith, Guffon, et al., 2009) indicates that all forms of NPD are a result of a spontaneous genetic mutation on chromosomes 11, 14, or 18 (Wraith, Guffon, et al., 2009). In NPD, lipids or fats collect in the cells of the spleen, liver and brain resulting in skin, eyes, musculoskeletal, nervous system, liver, and lymphoid organ disorders (Bi \& Liao, 2010; Lloyd-Evan et al., 2008; Santos et al., 2008; Xu et al., 2012). NPD occurs in all ethnic groups and in both males and females (Greer et al., 1997; Wraith, Guffon, et al., 2009). Early onset can occur anytime from prenatal through age two, but onset is more likely to occur during childhood between 4 and 10 years old (Crocker $\&$ Farber, 1958; Tang, Li, \& Liu, 2010; Winsor \& Welch, 1978). Therefore, children with NPD may be identified during the school years and will be attending school at onset and during the degeneration of involved systems. Classroom teachers and supporting personnel become an integral part of the team that observes and documents changes in student health and behaviors that impact student learning (National Neiman-Pick Disease Foundation [NNPDF], 2009). Therefore, a review of NPD and its characteristics is in order.

\section{DEFINITION}

The first written reports of NPD were by Albert Niemann in 1914 and Ludwig Pick in 1927. Both doctors described cases of infants who had "rapidly progressive neurodegeneration that subsequently led...to ...death" (Heath, 2008, p. 2). In 1958, Alan Crocker and Sidney Farber reviewed cases of 18 individuals with characteristics of this disease and, in 1961, proposed that NPD be divided into four groups or subtypes: A, B, C, and D (Tang, Li, \& Liu, 2010). Each of these subtypes was based on the time of onset and disease path. Interestingly, this action expanded the category of Niemann-Pick disease by applying the diagnosis to all patients with lipid storage issues and led to the inclusion of older, less severely affected individuals than those originally described by Niemann and Pick (National Organization for Rare Disorders [NORD], 2006). Regardless of the subtype, symptoms include "yellow discoloration of the skin, eyes, and/or mucous membranes (jaundice), progressive loss of motor skills, feeding difficulties, learning disabilities, and an abnormally enlarged liver and/or spleen (hepatosplenomegaly)" (NORD, 2006, p. 1). NPD is always fatal with many individuals dying before age 10 
Table 1.

Subtypes of Niemann-Pick Disease

\begin{tabular}{|l|l|}
\hline Subtype & Prognosis \\
\hline NPA: Classic or Severe Infantile Form & Death as an infant or toddler \\
\hline NPB: Visceral or Chronic Form & $\begin{array}{l}\text { Death by late childhood or early } \\
\text { adulthood depending on severity of } \\
\text { symptoms }\end{array}$ \\
\hline $\mathrm{NPC}_{1}$ : Sub acute or juvenile form & $\begin{array}{l}\text { Death within } 6 \text { to } 10 \text { years of diag } \\
\text { nosis; no later than } 15 \text { years old }\end{array}$ \\
\hline $\mathrm{NPC}_{2}$ : Nova Scotia variant & Same prognosis as $\mathrm{NPC}_{1}$ \\
\hline NPE: Adult onset & Unknown \\
\hline
\end{tabular}

and the majority dying before age 20 (Vanier, 2010; Wraith, Baumgartner, et al., 2009). See Table 1 for an overview of the NPD subtypes.

NPD is also divided by symptoms as well as by severity. NPA (classic form or severe infantile form) includes the earlier identified version wherein infants had neurodegenerative disease leading to death before age one. Those individuals with NPB (visceral or chronic form) have no brain or nervous system involvement, such as loss of motor skills, but may have respiratory problems. Both A and B are relatively rare subtypes with an approximate total of 1200 cases worldwide for both with the majority being those with NPB (NNPDF, 2010). Individuals with $\mathrm{NPC}_{1}$ (subacute or juvenile) have neurodegeneration (Bi \& Liao, 2009), but it occurs in a slower progression than it does in children with NPA. Approximately 500 cases of individuals with $\mathrm{NPC}_{1}$ have been identified worldwide, but this number is considered to be low as many other children may be under diagnosed or misdiagnosed (Wraith, Guffon, et al., 2009). Often $\mathrm{NPC}_{1}$ is initially diagnosed as "learning disability, mild retardation, 'clumsiness', and delayed development of fine motor skills" (NNPDF, 2010). NPD type D (Nova Scotia variant or Crocker-Farber syndrome) is a variant of $\mathrm{NPC}_{1}$ and has been found only in one area of Nova Scotia. It is now often called $\mathrm{NPC}_{2}$. The various forms of NPD are found throughout the world, thus affecting all ethnic groups, although there has been a higher incidence found in some populations worldwide, e.g., Ashkenazi Jewish families (NPA), the Maghreb region of Northern Africa (NPB), and Spanish-American families in New Mexico and Colorado (NPC 1 ) (Heath, 2008; NNPDF, 2010; Patterson, Vanier, et al., 2001; Winsor \& Welch, 1978). More recent research supports that $\mathrm{NPC}_{1}$ and $\mathrm{NPC}_{2}$ have different causation (Goldman \& Krise, 2010). 


\section{CHARACTERISTICS AND ACCOMMODATIONS}

Children with NPA and NPC both exhibit signs of neurodegeneration; however, children with NPC show a slower rate of neurodegeneration than children with NPA that often results in death before age one. Children with NPB exhibit only respiratory issues and seldom exhibit neurodegeneration. Consequently, only children with $\mathrm{NPC}_{1}$ may encounter classroom issues (Greer et al., 1997; Patterson, Vanier, et al., 2001). Therefore, this discussion will focus on symptomology of, and accommodations for, children with $\mathrm{NPC}_{1}$. According to Yanjanin et al. (2010), clinical signs can be noted "in nine major (ambulation, cognition, eye movement, fine motor, hearing, memory, seizures, speech and swallowing) and eight minor (auditory brainstem response, behavior, gelastic cataplexy, hyper reflexive, incontinence, narcolepsy, psychiatric, and respiratory problems) domains" (p. 132). Issues in the domains represented in the previous quote (physical health, fine and gross motor, speech and language, and cognition) are important educational domains and, therefore, important to the student's educational program, either in the IEP-related documents or in the Section 504 plans. Based on reviews of the extant literature on NPC, the authors developed this discussion of possible educational accommodations for classroom use. The authors based the selected accommodations on their extensive experience in the field of education of children with disabilities and how the characteristics of children with NPC could impact their educational experience. Thus, suggestions for working with these issues follow and are summarized in Table 2.

\section{HEALTH ISSUES}

The physical health of the child is often the first indicator of the presence of NPD (Patterson, Vanier, et al., 2001). This is compounded, though, with the fact that it is an exceptionally variable condition. Symptoms of the disease are shared by other lysosomal disorders and the rate of disease progression is variable. These two factors make it difficult to conclusively diagnosis $\mathrm{NPC}_{1}$ (NNPDF, 2011). One of the first physical signs is an enlarged abdomen along with an enlarged spleen. In addition, liver disease may occur (Tangermo et al., 2011). Children with $\mathrm{NPC}_{1}$ often have respiratory issues and an insufficiency in respiration that may lead to reoccurring bouts of respiratory infections.

As a result of the physical health issues, many of these student will be absent from school and the school will need to identify the student as in need of special education services under the regulations identifying students with Other Health Impairments. Based on the student's needs the school may need to have hospital/homebound services available to maintain the continuity of 
the student's education program. When in attendance at school, students may need to be observed by the teacher or an identified classroom adult so that parents may be contacted about the possible onset of respiratory or other health issues. Care should be taken to reduce exposure to classroom sources of respiratory infections. Universal precautions should be observed to reduce the spread of infection. For example, frequent hand washing and equipment disinfection should be the rule.

\section{MOTOR ISSUES}

Teachers may notice the presence of issues with delay or regression in either or both fine and gross motor development. With the onset of the disease, delayed performance of motor milestones may occur. Gait problems, perhaps seen as clumsiness, will emerge. The gait issues seem to be compounded by balance issues, hypotonia (decreased muscle tone), and resultant ataxia (frequent falls) (Tangermo et al., 2011). As the disease progresses, dysphagia (difficulty swallowing) may be noticed during lunch time. In addition, some children experience hand tremors, backward head thrust, and seizures (Patterson, 2009; Patterson, Vanier, et al., 2001). For those activities that are impacted by the student's increasing problems with motor coordination, the teacher can provide a number of changes to the classroom. Within the classroom, teachers should clear walkways and position backpacks, tables, chairs, desks, objects, etc., so that they are not an impediment to the student. The student's desk should be placed close to materials and the work areas for easier access. As the disease progresses, a personal assistant may need to help the student to move about the classroom and the school and to provide other personal services as needed. It is the responsibility of the teacher to provide a physically safe environment for the student. As a result not only the classroom teacher but the occupational therapist may need to be involved in developing appropriate activities for the student.

A request for assistance from the Occupational Therapist (OT) should be made when the teacher needs additional strategies for meeting the fine motor challenges of students. The OT can provide information and materials to support the student who is having hand, grasp, and finger issues. As a member of the student support team, OTs can choose appropriate adaptive equipment and teach the student, teacher and family members in its correct use. Also, OTs can support the student and teachers by modifying classroom equipment and providing strategies to help students participate as fully as possible in school activities.

In response to the fine motor issues, the classroom teacher may need to adapt student assignments that would usually be completed in written format 
and allow them to be submitted using a word processing program or an audio recorder. If the student is willing, a scribe can be identified who will write the student's answers. When this is not a possibility, a non-written assignment can be substituted. Copying homework assignments and various written language activities from the board is often used in classrooms. For children who are experiencing Vertical Supranuclear Gaze Palsy (VSGP), or the inability to voluntarily raise and lower their eyes, this is extremely difficult. A substitute activity could be provided or a copy of any homework assignments given to the student in lieu of requiring the copying activity.

For a student who has issues with balance and gait, a request for a Physical Therapist evaluation is appropriate. Also, the student may benefit from the services of an Adaptive Physical Education (APE) instructor who can provide information and training on physical education and recreational activities that will allow the student to physically participate in school activities as long as possible.

\section{SPEECH AND LANGUAGE ISSUES}

Parents and teachers will often begin to notice a change in the speech and language ability of children with $\mathrm{NPC}_{1}$. One of the first symptoms is the delayed language acquisition, as some parents note that their children's language has not only slowed but, in fact, is decreasing. In addition, children may exhibit dysarthria, wherein the muscles that help with speech begin to lose the ability to form words, resulting in word slurring and speech that is difficult to understand. As the disease progresses many children begin to exhibit aphasia, wherein they forget the words to use for objects. Teachers should be aware of ways to assist students with continuing to participate in classroom activities and interacting with peers.

Preserving language and speech communication are essential to prevent the student from becoming prematurely isolated. For some children, one of the first language losses they may encounter is an inability to find words to use in conversation or to answer questions. A photo/picture board with the student's most used words or activities can be prepared to help. There are a number of computer programs that can be used to print pictures or that can be used on a tablet, personal computer, or smartphone. Because of memory issues, the student may have difficulty with time awareness or be unable to remember when to move to a new activity. The teacher and student may develop verbal cues or physical signals as a prompt. One method using visual cues is to use a digital camera to make an individualized schedule board for the student's daily activities.

As the disease progresses, the student will need to have support and assistance from the Speech and Language Pathologist (SLP) because of the 
presence of language delay, dysarthria, and aphasia issues associated with $\mathrm{NPC}_{1}$, as well as the issues related to eating and swallowing. The SLP can provide the teacher with information and strategies for the management, intervention, and treatment of both language and swallowing issues.

\section{COGNITIVE ISSUES}

One of the most difficult groups of characteristics for teachers revolves around changes in the brain. This group of symptoms is the reason that this disease is often called "childhood dementia" or "childhood Alzheimer's disease" (Imrie, Jacklin, \& Mathieson, 2009; NNPDF, 2011). One of the early neurological indicators is when the child begins to have difficulty with voluntarily raising his/her eyes in a vertical motion, known as Vertical Supranuclear Gaze Palsy (VSGP) (Patterson, 2009; Patterson, Vanier, et al., 2001; Tang, Li, \& Liu, 2010; Tangermo et al., 2011). A second indicator is when the child begins to exhibit cataplexy, which is a sudden loss of muscle tone and falling, often triggered by some emotion. For children with $\mathrm{NPC}_{1}$, this has been noted as occurring when activities arouse emotional responses or laughter (Patterson, 2009; Patterson, Vanier, et al., 2001).

The most significant characteristic for the school age child, though, is the gradual loss of mental ability; i.e., the onset of dementia (Imrie, Jacklin, \& Mathieson, 2009). Children begin to lose their ability to concentrate on academic activities. They no longer have the ability to remember information, especially information in short-term memory. Additionally, their ability to learn new material begins to decrease. For children who reach adolescence, psychosis may appear in the form of paranoid delusions, auditory or visual hallucination, and interpretative thoughts (NNPDF, 2011; Tangermo et al., 2011). Episodes of depression and aggressive behavior may also begin to appear (Patterson, 2009; Patterson, Vanier, et al., 2001).

To assist students in being successful during the classroom day, transitional class routines should be established. This consistency in change-up times will help the student who has difficulty with time considerations and memory. When memory loss occurs, children may forget the location of their desks, materials, and books. To reduce the anxiety or behavioral outbursts that may result when the student is unable to find his/her materials, the student's name can be attached to his/her desk, cubby, books, tables, etc. As the student's memory continues to deteriorate, schematic drawings or flow charts with photos can be used as memory cues for daily activities allowing the student, peers, or aide to more easily locate his /her place in the classroom. 
Table 2 .

Accommodations for Individuals with NPD

\section{Health Accommodations}

- Know and use Universal Precautions within the classroom

- Thoroughly disinfect desks and equipment at least once a day

- Have disinfect wipes available for student use in the classroom

- Keep infectious students at a distance from the student with NPD

- Notify parents of student with NPD if the child becomes ill or if others are ill in the classroom

- Implement a system to send homework to student when he/she is absent (computers can be used)

- Implement a system where students at school can visit the student with NPD when student is absent perhaps using skype or facetime or other electronic or digital avenues

- Arrange for hospital/homebound services before they are needed

\section{Fine Motor Accommodations}

- Use word processor or tape recorder in place of written assignments

- Ask a peer to serve as a scribe

- Assign non-written assignment options

- Provide a substitute activity for copying from the board

- Request Occupational Therapist support for hand, grasp and finger issues

\section{Gross Motor Accommodations}

- Keep walkways clear

- Place student desk close to materials or work area

- Provide personal assistant

- Request Physical Therapist support for gait \& balance

- Utilize services of Adaptive Physical Education instructor for Physical Education and recreational activities

\section{Speech and Language Accommodations}

- Provide student with a digital camera to make a schedule board to cue activities 


\section{Table 2. (Continued)}

- Use a photo/picture board for language starters

- Utilize speech/language pathologist support for speech and swallowing concerns

\section{Cognitive Accommodations}

- Establish transitional class routines

- Use schematic drawings or flow charts as memory cues for daily activities

- Provide pre-transition warnings \& cue activities with music

- Label items when word memory fails

- Use text to speech applications

- Provide a quiet work area

- Provide peer support

- Prepare a photo or video daily school/home diary

Reading textbooks for information access or for relaxation can become difficult as children begin to lose their ability to remember and understand written words. The use of a text-to-speech application can be useful. The provision of peer support or a peer buddy to assist the student throughout the day can be very helpful. The peer can ensure that the student has his/her materials and is cued for the correct activity. More so, a peer can offer a feeling of comfort or assurance to the student.

Peers, as well as the student, can use a digital camera (still or video) to provide a daily diary that can be taken home. This can be a used as a communication tool by the parents as well as a memory tool to assist the student in telling about his/her day. The parents can then do the same at home with the student bringing the photo/video to school each morning. Over time, this diary can provide a diagnostic observational tool to track the change in the student's abilities.

To decrease the chances of behavioral outbursts and/or occurrences of cataplexy, pre-transition warnings should be given to the student. These can be in oral or visual format. Music is one of the last items to be forgotten so pairing certain musical phrases with specific activities can assist the student in remembering what the activity is and what he/she should do. A quiet work or relaxation area may be needed to provide the student an environment with less stimulation since she/he may become anxious or over stimulated with the noise and activity in a typical school classroom. In addition, the child often recognizes the loss of ability, especially early on in the disease progression, and this may result in anxious moments and/or depression. 


\section{EMOTIONAL ISSUES}

A significant concern for the student's family and teacher is that the deterioration of language and physical skills may result in social isolation for the student. Therefore, as the disease progresses, teachers will need a variety of accommodations to allow the student to continue to participate both educationally and socially in the classroom. A Counselor may be added to provide emotional support to the student with $\mathrm{NPC}_{1}$ and his/her family, the student's classmates, and the teachers and support staff involved with the student.

Thus, for the teacher who has a student with $\mathrm{NPC}_{1}$ in the classroom, the focus becomes two-fold. Support for both the family and the student must occur. To assist the family in knowing how the student is doing physically, emotionally, and educationally during the school day, daily notes can be sent home to the parents. The manner of submission will depend on the family and their wish to receive notes in written or digital format. In addition, online or written information about current and future assignments, and activities such as field trips should be provided to the parents so that they can prepare and assist their student.

Identification and connection with community or national support groups is essential for the parents of a student with a progressive, fatal disease such as $\mathrm{NPC}_{1}$. In addition, teachers "will need to develop, within their own establishments, a support system to help each other deal with the emotional feelings often experienced when working with people who have a terminal condition" (NNPDF, 2011). Of course, the teacher can use many of the

Table 3 .

\section{Informational and Support Groups}

\begin{tabular}{|l|l|}
\hline $\begin{array}{l}\text { National Niemann-Pick Disease } \\
\text { Foundation }\end{array}$ & www.nnpdf.org \\
\hline Niemann-Pick Disease Group (UK) & www.niemannpick.org.uk \\
\hline National Library of Medicine & ghr.nlm.nih.gov/condition/niemann-pick \\
\hline NIH: Office of Rare Diseases & rarediseases.info. \\
\hline Medline Plus & nlm.nih.gov/medlineplus \\
\hline $\begin{array}{l}\text { Ara Parseghian Medical Research } \\
\text { Foundation }\end{array}$ & www.parseghian.org \\
\hline Race for Adam & www.raceforadam.org \\
\hline Mayo Clinic & www.mayoclinic.org/niemann-pick \\
\hline Rare Disease Network & $\begin{array}{l}\text { rarediseasesnetwork.epi.usf.edu/ } \\
\text { stair/NPC }\end{array}$ \\
\hline
\end{tabular}


activities noted above within the classroom during the early stages of the disease progression. Teachers will need to check the student's records and then seek further assistance from the personnel described previously. In order to use the skills of all suggested support personnel, a request for special education and subsequent IEP or Section 504 plan development should occur. A student with Niemann-Pick Disease, Type C, will require the combined skills of a team of educators and related support personnel.

\section{SUMMARY}

Niemann-Pick Disease, Type C, is a disease that presents many issues for the student, the parents, and the student's teacher. Knowledge of the disease, its characteristics, and its progression is essential for the teacher to provide an appropriate educational experience for the student. The team approach in developing IEP or Section 504 plans is essential because of the complexity of the disease. Teachers play a key role in coordinating the therapeutic programs recommended by the health professionals. For the teacher who has a student with $\mathrm{NPC}_{1}$ in his/her classroom, the mission is two-fold: first to provide a supportive academic environment for the student with $\mathrm{NPC}_{1}$ and classroom peers; and, second, to provide emotional support for the student and the family. Identification and connection with community or national support groups may be helpful to both parents and others in the school community. Teachers and service providers may also need to develop a support system to help each other deal with the feelings accompanying a student's illness and death. The steps identified by the authors of this manuscript can provide teachers with a prototype for the steps to use when a student with a rare syndrome or another unfamiliar disorder can use to identify characteristics which may impact on the student's educational success and will need classroom revisions and/or request for related personnel support.

\section{REFERENCES}

Bergamin, N., Darchis, A., Beltrami, A., Cesselli, D., Rigo, S., et al. (2013). A human neuronal model of Niemann-Pick C disease developed for stem cells isolated from patient's skin. Orphanet Journal of Rare Disorders, 8, 34.

Bi, X. \& Liao, G. (2007). Autophagic-lysosomal dysfunction and neurodegeneration in Niemann-Pick type C mice: Lipid starvation or indigestion? Autophagy, 3, 646-648. 
Bi, X. \& Liao, G. (2010). Cholesterol in Niemann-Pick type C disease. Subcellular Biochemistry, 51, 319-335.

Crocker, A. C. \& Farber, S. (1958). Niemann-Pick disease: A review of 18 patients. Medicine, 37, 1-95.

Goldman, S. D. B. \& Krise, J. P. (2010). Niemann-Pick C1 functions independently of retrograde transport of membrane-impermeable lysosomal cargo. Journal of Biological Chemistry, 285, 4983-4994.

Greer, W. L., Riddell, D. C., Byers, D. M., Welch, J. P., Girouard, G. S., Sparrow, S. M., Gillan, T. L., \& Neumann, P. E. (1997). Linkage of Niemann-Pick disease type D to the same region of human chromosome 18 as Niemann-Pick disease type C. American Journal of Human Genetics, 61, 139-142.

Heath, J. (2008). Clinical characteristics of Niemann Pick type C in New Mexican patients. SOM Medical Student Research Papers. Albuquerque, NM: University of New Mexico. Retrieved from http://hdl.handle.net/1928/9763

Imrie, J., Jacklin, E., \& Mathieson, T. (2009). Dementia in children, teenagers and young adults: A guide for parents, teachers and care professionals. Stirling, Scotland, UK: University of Scotland.

Knox, R. A. \& Ramsey, G. W. (1932). Niemann-Pick's disease: (Essential lipoid histiocytosis). Annals of Internal Medicine, 6, 218-226.

Lloyd-Evan, E., Morgan, A. J., He, X., et al. (2008). Niemann-Pick disease type $\mathrm{C} 1$ is a sphingosine storage disease that causes deregulation of lysosomal calcium. Nature Medicine, 14, 1247-1255.

National Niemann-Pick Disease Foundation (NNPDF). (2009). General information on educational management for young people with Niemann-Pick type C. Retrieved from http://www.nnpdf.org/familyservices_13.html

National Niemann-Pick Disease Foundation (NNPDF). (2010). NiemannPick disease overview. Retrieved from http://www.nnpdf.org/npdisease_01.html

National Niemann-Pick Disease Foundation (NNPDF). (2011). The Niemann-Pick Disease Foundation brochure. Fort Atkinson, WI: NNPDF.

National Organization for Rare Disorders (NORD). (2006). Niemann Pick Disease. Retrieved from https://myhealth.alberta.ca/Health/Pages/

Patterson, M. C. (2009). Niemann-Pick disease type C-The challenge of diagnosis and treatment. European Paediatrics, 3, 10-13.

Patterson, M. C., Vanier, M. T., Suzuki, K., Morris, J. A., Caresta, E., Neufeld, E. B., Blanchette-Mackie, J. E., \& Pentchev, P. G. (2001). NiemannPick Disease type C: A lipid trafficking disorder. In C. R. Scriver, 
A. L. Beaudet, W. E. Sly, \& D. Valle (Eds.), The metabolic and molecular bases of inherited disease (8th ed.) (pp. 3611-3634). NY: McGrawHill.

Rodriguez-Pascau, L., Coll, M. J., Casas, J., Vilageliu, L., \& Grinberg, D. (2012). Generation of a human neuronal stable cell model for Niemann-Pick C disease by RNA interference. Journal of Inherited Metabolic Disorders Reports, 4, 29-37.

Santos, M. L., Raskin, S., Telles, D. S., Lohr, A. J., et al. (2008). Treatment of a child diagnosed with Niemann-Pick disease type $\mathrm{C}$ with miglustat: A case report in Brazil. Journal of Inherited Metabolic Disorders, 2, S357-S361.

Tang, Y., Li, H. \& Liu, J. (2010). Niemann-Pick disease type C: From molecule to clinic. Clinical \& Experimental Pharmacology \& Physiology, 37, 132-140.

Tangermo, C., Weber, D., Theiss, S., Mengel, E., \& Runz, H. (2011). Niemann-Pick type $\mathrm{C}$ disease: Characterizing lipid levels in patients with variant lysosomal cholesterol storage. Journal of Lipid Research, 52, 813-825.

Vanier, M. T. (2010). Niemann-Pick disease type C. Orphanet Journal of Rare Diseases, 5, 1-18.

Winsor, E. J. T. \& Welch, J. P. (1978). Genetic and demographic aspects of Nova Scotia Niemann-Pick Disease (Type D). American Journal of Human Genetics, 30, 530-538.

Wraith, J. E., Baumgartner, M. R., Bembi, B., Covanis, A., Levade, T., Mengel, E., Pineda, M., Sedel, F., Topcu, M., Widner, H., Vanier, M. T., Wijburg, F. A., \& Patterson, M. C. (2009). Recommendations on the diagnosis and management of Niemann-Pick disease type C. Molecular Genetics and Metabolism, 98, 152-165.

Wraith, J. E., Guffon, N., Rohrbach, M., Hwu, W. L., Korenke, G. C., Bembi, B., Luzy, C., Giorgino, R., \& Sedel, F. (2009). Natural history of Niemann-Pick disease type $\mathrm{C}$ in a multicentre observational retrospective cohort study. Molecular Genetics and Metabolism, 98, 250-254.

Yanjanin, N. M., Velez, J. L., Gropman, A., King, K., et al. (2010). Linear clinical progression, independent of age of onset in Niemann-Pick disease, type C. American Journal of Medical Genetics Part B: Neuropsychiatric Genetics, 153B, 132-140.

Xu, M., Liu, K., Swaroop, M., Porter, F. D., Sidhu, R., Fimkes, S., et al. (2012). d-Tocopherol reduces lipid accumulation in Niemann-Pick type $\mathrm{C} 1$ and Wolmen cholesterol storage disorders. Journal of Biological Chemistry, 287, 39349-39360. 


\section{APPENDIX}

References with digital object identifiers (DOI) added:

Bergamin, N., Darchis, A., Beltrami, A., Cesselli, D., Rigo, S., Zamperini, S., ... Beltrami, C. A. (2013). A human neuronal model of Niemann-Pick C disease developed for stem cells isolated from patient's skin. Orphanet Journal of Rare Disorders, 8, 34. http://dx.doi.org/10.1186/1750-1172-8-34

Bi, X. \& Liao, G. (2007). Autophagic-lysosomal dysfunction and neurodegeneration in Niemann-Pick type C mice: Lipid starvation or indigestion? Autophagy, 3, 646-648. http://dx.doi.org/10.4161/auto.5074

Bi, X. \& Liao, G. (2010). Cholesterol in Niemann-Pick type C disease. Subcellular Biochemistry, 51, 319-335. http://dx.doi.org/10.1007/978-90-481-8622-8_11

Crocker, A. C. \& Farber, S. (1958). Niemann-Pick disease: A review of 18 patients. Medicine, 37, 1-95. http://dx.doi.org/10.1097/00005792-195802000-00001

Goldman, S. D. B. \& Krise, J. P. (2010). Niemann-Pick C1 functions independently of retrograde transport of membrane-impermeable lysosomal cargo. Journal of Biological Chemistry, 285, 4983-4994. http://dx.doi.org/10.1074/jbc.M109.037622

Greer, W. L., Riddell, D. C., Byers, D. M., Welch, J. P., Girouard, G. S., Sparrow, S. M., Gillan, T. L., \& Neumann, P. E. (1997). Linkage of Niemann-Pick disease type D to the same region of human chromosome 18 as Niemann-Pick disease type C. American Journal of Human Genetics, 61, 139-142. http://dx.doi.org/10.1086/513899

Heath, J. (2008). Clinical characteristics of Niemann Pick type C in New Mexican patients. SOM Medical Student Research Papers. Albuquerque, NM: University of New Mexico. Retrieved from http://hdl.handle.net/1928/9763

Imrie, J., Jacklin, E., \& Mathieson, T. (2009). Dementia in children, teenagers and young adults: A guide for parents, teachers and care professionals. Stirling, Scotland, UK: University of Scotland.

Knox, R. A. \& Ramsey, G. W. (1932). Niemann-Pick's disease: (Essential lipoid histiocytosis). Annals of Internal Medicine, 6, 218-226. http://dx.doi.org/10.7326/0003-4819-6-2-218

Lloyd-Evan, E., Morgan, A. J., He, X., et al. (2008). Niemann-Pick disease type C1 is a sphingosine storage disease that causes deregulation of lysosomal calcium. Nature Medicine, 14, 1247-1255. http://dx.doi.org/10.1038/nm.1876

National Niemann-Pick Disease Foundation (NNPDF). (2009). General information on educational management for young people with Niemann-Pick type C. Retrieved from http://www.nnpdf.org/familyservices_13.html 
National Niemann-Pick Disease Foundation (NNPDF). (2010). Niemann- Pick disease overview. Retrieved from http://www.nnpdf.org/npdisease_01.html

National Niemann-Pick Disease Foundation (NNPDF). (2011). The Niemann-Pick Disease Foundation brochure. Fort Atkinson, WI: NNPDF.

National Organization for Rare Disorders (NORD). (2006). Niemann Pick Disease. Retrieved from https://myhealth.alberta.ca/Health/Pages/

Patterson, M. C. (2009). Niemann-Pick disease type C-The challenge of diagnosis and treatment. European Paediatrics, 3, 10-13.

Patterson, M. C., Vanier, M. T., Suzuki, K., Morris, J. A., Caresta, E., Neufeld, E. B., Blanchette-Mackie, J. E., \& Pentchev, P. G. (2001). Niemann-Pick Disease type C: A lipid trafficking disorder. In C. R. Scriver, A. L. Beaudet, W. E. Sly, \& D. Valle (Eds.), The metabolic and molecular bases of inherited disease (8th ed.) (pp. 3611-3634). NY: McGraw-Hill.

Rodriguez-Pascau, L., Coll, M. J., Casas, J., Vilageliu, L., \& Grinberg, D. (2012). Generation of a human neuronal stable cell model for Niemann-Pick C disease by RNA interference. Journal of Inherited Metabolic Disorders Reports, 4, 29-37.

Santos, M. L., Raskin, S., Telles, D. S., Lohr, A. J., et al. (2008). Treatment of a child diagnosed with Niemann-Pick disease type $\mathrm{C}$ with miglustat: A case report in Brazil. Journal of Inherited Metabolic Disorders, 2, S357-S361. http://dx.doi.org/10.1007/s10545-008$\underline{0923-9}$

Tang, Y., Li, H. \& Liu, J. (2010). Niemann-Pick disease type C: From molecule to clinic. Clinical \& Experimental Pharmacology \& Physiology, 37, 132-140. http://dx.doi.org/10.1111/j.1440-1681.2009.05235.x

Tangermo, C., Weber, D., Theiss, S., Mengel, E., \& Runz, H. (2011). Niemann-Pick type C disease: Characterizing lipid levels in patients with variant lysosomal cholesterol storage. Journal of Lipid Research, 52, 813-825. http://dx.doi.org/10.1194/jlr.P013524

Vanier, M. T. (2010). Niemann-Pick disease type C. Orphanet Journal of Rare Diseases, 5, 118. http://dx.doi.org/10.1186/1750-1172-5-16

Winsor, E. J. T. \& Welch, J. P. (1978). Genetic and demographic aspects of Nova Scotia Niemann-Pick Disease (Type D). American Journal of Human Genetics, 30, 530-538.

Wraith, J. E., Baumgartner, M. R., Bembi, B., Covanis, A., Levade, T., Mengel, E., ... Patterson, M. C. (2009). Recommendations on the diagnosis and management of Niemann-Pick disease type C. Molecular Genetics and Metabolism, 98, 152-165. http://dx.doi.org/10.1016/j.ymgme.2009.06.008 
Wraith, J. E., Guffon, N., Rohrbach, M., Hwu, W. L., Korenke, G. C., Bembi, B., ... Sedel, F. (2009). Natural history of Niemann-Pick disease type $C$ in a multicentre observational retrospective cohort study. Molecular Genetics and Metabolism, 98, 250-254. http://dx.doi.org/10.1016/j.ymgme.2009.06.009

Yanjanin, N. M., Velez, J. L., Gropman, A., King, K., et al. (2010). Linear clinical progression, independent of age of onset in Niemann-Pick disease, type C. American Journal of Medical Genetics Part B: Neuropsychiatric Genetics, 153B, 132-140.

Xu, M., Liu, K., Swaroop, M., Porter, F. D., Sidhu, R., Fimkes, S., ... Zheng, W.(2012). Tocopherol reduces lipid accumulation in Niemann-Pick type $\mathrm{C} 1$ and Wolmen cholesterol storage disorders. Journal of Biological Chemistry, 287, 39349-39360. http://dx.doi.org/10.1074/jbc.M112.357707 